\title{
Application-oriented Undergraduate "Internet +" Software Engineering Textbook Construction
}

\author{
Li Tianli, Zhang Jinbo \\ (School of Computer Engineering, City Institute, Dalian University of Technology, Dalian \\ Liaoning 116600, China)
}

\begin{abstract}
Keywords: Applied Undergraduate; Internet + Textbook; Software Engineering Course; WeChat Platform; Cloud Platform; Learning Behavior Analysis;
\end{abstract}

\begin{abstract}
In the era of "Internet +", the application-oriented undergraduate universities are undergoing pilot transformation. Under the new form, the construction of teaching materials is in a period of vigorous development. It is imperative for software engineering majors to adapt to the goal of cultivating applied-type talents, and the reform of teaching materials is imperative. Paying equal attention to practice, it is more representative and popularized for the reform of teaching materials. Therefore, the author puts forward the software project "Internet + teaching material" which is deeply integrated with traditional teaching materials, digital resources and mobile devices, and expounds the characteristics and specifics of the textbook. The construction plan emphasizes the precautions for the preparation of paper textbooks, the construction framework of the cloud platform, the construction and use of mobile platforms, and the design of intelligent resource push. It also has reference to the construction of other textbooks. Finally, it gives out the "Internet + " Textbooks issues what require further research.

CLC number: G642 Document code: A
\end{abstract}

\section{Introduction}

In 2014, the State Council launched a pilot project for the transformation of non-research general undergraduate colleges to applied technology. The software engineering profession implemented school-enterprise cooperation, integration of production and education, and met the goal of cultivating applied technology and skill-based innovative entrepreneurial talents. "Internet + " is a new form and new format of Internet development under Innovation 2.0. "Internet + teaching materials" is a new form of traditional textbooks that use mobile Internet, cloud computing, big data and other information and communication technologies to transform the compilation, publication and use of the original textbooks, and deeply integrate traditional education and Internet platforms.

The software engineering course is the core course of software engineering. The theory and practice are equally important. The traditional textbooks are theoretically strong, and the resources are limited. The information expression technique is single. Students often feel that abstract empty holes are boring, software engineering technology update speed is fast, and the case is adopted. It is often low in level and backward in technology. It does not reflect the actual projects and cutting-edge technologies of enterprises. The teaching effect is poor, the students are small, and they are out of line with the needs of enterprises. This is not conducive to the development of the application of technical and technical talents.

If the traditional paper textbooks, digital platform (boutique video open class, boutique resource sharing class) and mobile devices can be deeply integrated, it will be a hot topic in the current textbook construction research to stimulate students' independent learning, inquiry learning and cooperative learning.

\section{Textbook Characteristics}

(1) The textbooks paper are thin and fine, and there are a lot of teaching materials in the background. The paper textbook emphasizes applicability, practicality and applicability, incorporates as many new technologies as possible, and eliminates the use of technology that is abandoned. In addition to the 
basic principles, techniques, methods and tools emphasized by traditional textbooks, the background includes micro-courses, instructional videos, QR code materials, courseware, lesson plans, syllabus, teaching plans, answers to after-school exercises, test papers and reference answers, test questions, etc. numerous teaching documents and teaching information to ensuring the breadth and continuity of student learning.

(2) Teaching resources are flexible in expression and increase students' interest in learning. In addition to traditional texts and diagrams, back-end web pages, animation, audio, video, and microcourses have changed the single and inadequate traditional teaching resources it also is conducive to students' self-learning and re-learning ability.

(3) A corporate project-oriented teaching case. Close cooperation with enterprises, complementary advantages, not only focus on the expansion of knowledge, but also highlight the professional quality and work ability training, establish a software engineering practice textbook with the main line of enterprise project practice, theory and practice.

(4) Use the QR code to present course resources. Paper textbooks serve as the backbone of the information carrier of "Internet + Textbooks". The key points and main lines are clear. The extended knowledge points use QR codes. Readers can quickly locate the knowledge points on the Internet by scanning mobile phones or mobile devices with QR codes. Guide students to digital courses to deepen their learning and expand their learning. The construction of cloud platform and WeChat platform is the key support environment for QR code presentation resources. In particular, WeChat social media technology based on "Internet +" can effectively improve students' interest in learning, exert subjective initiative, improve learning participation, and meet the needs of personalized and differentiated learning.

(5) The deep integration of online and offline learning has realized personalized learning and collaborative learning in the "Internet Plus" mode. The "Internet + Textbook" is deeply integrated with the cloud platform and WeChat platform, achieving the goal of student fragmentation learning, mobile learning and ubiquitous learning. Online learners can get the information they want at any time and any place, make full use of the fragmentation time, and realize the autonomous learning in the true sense. Under the line, they will guide the classroom teaching of the core knowledge points and practical points of the paper textbooks. Students comprehensively master the knowledge architecture of software engineering and improve the actual combat capability of software development projects.

\section{Implementation Plan}

The overall framework for the implementation of software engineering "Internet + teaching materials" is shown in Figure 1. 


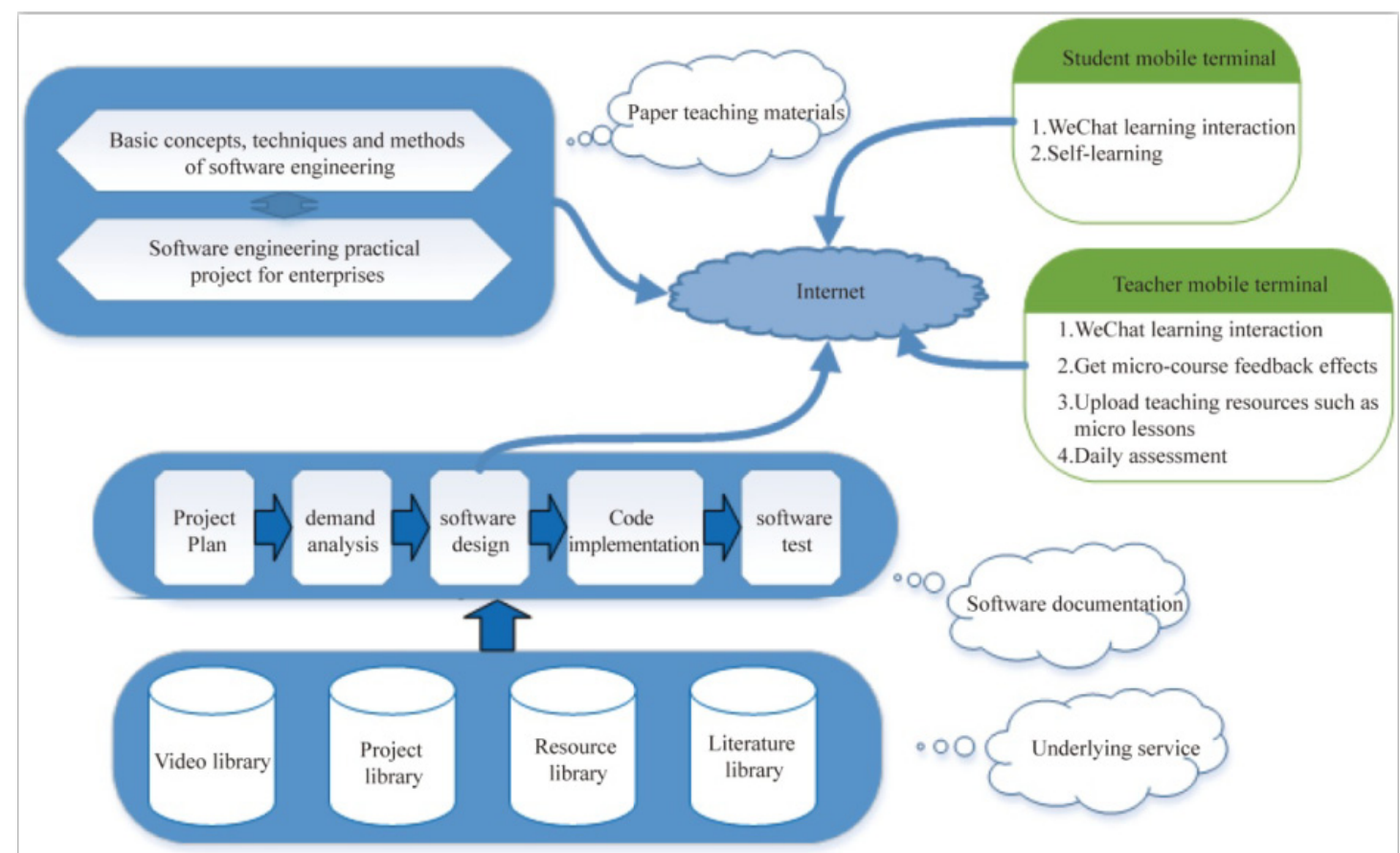

Figure 1 The overall framework for the implementation of the software project "Internet + Teaching Materials"

\subsection{Paper Textbook}

The paper teaching materials adopt the case-based teaching method, adapting to the application technology transformation of colleges and universities through cases, experiments, projects, and selected exercises, and the practice is strong. Explain important software engineering concepts, techniques, and methods for any programming language through a large number of cases; introduce the use of common software engineering tools through a large number of experiments, including software analysis and design modeling tools Microsoft Visio, object-oriented modeling tool Rational Rose, database analysis and design modeling tool PowerDesigner, project management tool Project, etc.; through two integrated projects, showing the whole process of structured and object-oriented software analysis, design and implementation; through the selected exercises in each chapter, deepen the further understanding understands the main concepts.

\subsection{Cloud Platform}

The established cloud platform is a guarantee for providing rich resources for teaching materials. The bottom layer is the service layer, which provides storage for various teaching resources, including resource libraries, video libraries, project libraries and document libraries, providing necessary foundations and rich resources for user services. Meet the students' pre-study and after-school digestion and promotion; the middle layer, in the massive data, according to the software engineering thinking (ie project planning, requirements analysis, design, coding, testing) to generate various software development documents, guidance Students carry out real software project development; the top level is the online learning layer, students can learn in advance, enhance the understanding of knowledge after class, make up for the lack of classroom information, expand the ability of students to learn again, online micro-course coverage software Students can find the knowledge points they need at any time and place, and then explain the difficulties and key points through the teacher theory class. Students can find the right direction, master the core of knowledge, and expand knowledge through new technologies and new horizons, the extensive and continuous knowledge and skills to meet the needs of students.

\subsection{Software Engineering Micro-Teaching Platform Based on Mobile Network WeChat Public Number}

WeChat platform is the use of teaching materials to achieve the elements of push teaching resources, 
interactive learning, self-learning, fragmented learning, mobile learning and ubiquitous learning. The WeChat platform mainly includes a back-end database server, a student terminal and a teacher terminal. The database server public cloud platform database mainly implements the storage microcourse resource library, statistical analysis of micro-course hits, intelligent push of similar videos, teaching interaction, and establishment of Lucene full-text search library. Lucene is a Java-based search library that can be used to index and search almost any type of text, providing the core business of any search application needed: indexing and searching. The process of searching for an application: getting the original content, building the document, analyzing the bins, and indexing the document. The student terminal mainly includes two modules of WeChat learning interaction and self-learning teaching materials. The teacher's side includes teaching and teaching interaction, obtaining microcourse feedback results, uploading teaching resources such as micro-courses and PPT, and several major modules for daily assessment.

\subsection{Online Learning Behavior Analysis and Intelligent Push}

How to capture the vast amount of information in the textbook, how to quickly capture online learning behavior and how to implement intelligent push is also a problem to be studied in the textbook. Firstly, the data mining analysis method is used to study the learner's online learning behavior and establish a model [10]. Then, through the data collection of the cloud platform and the WeChat platform, and based on the established model, intelligent push is implemented to improve the learning effect of the learner. Optimize the digital background design of teaching materials to provide services. The analysis of e-learning behavior mainly involves mining data from two parts: firstly, mining the reader's access log, mainly through the Web log explorer and analog tools to implement statistical analysis, discovering the pages frequently visited by readers, watching videos, and visiting websites. Volume and other content, help improve the structure, content, site cache and other content of the website; Secondly, mine the back-end database, the database server uses SQL Server 2012, through its own functions, according to the steps of "establishing business intelligence", the implementation of data import, Mining, statistics and analysis, recording a large amount of information such as readers' registration information, online exams, comments, online discussions, etc., can find out the reader's utilization of the cloud platform and WeChat platform, can help the editor to better understand the reader, and thus be targeted The digital resources are updated to realize the intelligent push of learning resources. Through the analysis and mining of learning behaviors, learning patterns, learning habits and cognitive levels, the readers are classified, so as to realize the automatic push of learning resources, to meet the current teaching in accordance with their aptitude, and to provide personalized service design ideas.

\section{Conclusion}

We have completed the preparation of paper textbooks, the establishment of learning behavior analysis models, the cloud platform and WeChat platform are under construction, use and iterative development. The textbooks are published by Huazhong University of Science and Technology Press. This is a preliminary study of "Internet + teaching materials". There are still many places that need innovation and improvement. The construction of "Internet + teaching materials" not only needs to prepare a large amount of information, but also needs the construction of various platforms. Followup consideration is to establish a unified website platform, which facilitates the rapid transplantation of writers of other teaching materials, reduces the time for platform development, and puts the energy mainly. In the development of teaching materials and video. "Internet + teaching materials" is not a simple paper textbook carrier to move, need to strengthen the interaction effect, the interaction of WeChat platform is only one aspect, you can consider the addition of virtual simulation, scenario simulation, interactive experiment, animation and other elements. How can various digital terminal devices have a good user experience? Although the WeChat platform usage rate and interface are popular with readers, it is possible to develop a compatible PC and mobile APP that is more conducive to the security and intellectual property of digital resources. protection. Finally, it should be noted that in order to develop "Internet + teaching materials", it takes a lot of manpower and material 
resources, but if it is only a decoration, the students' utilization rate is low, it is also a failure. How can we fully mobilize the students' subjective initiative and truly realize the students? The goal of fragmented learning, mobile learning and ubiquitous learning, teachers beyond the classroom, beyond the traditional paper materials, and improve the teaching effect are worth exploring.

\section{Acknowledgements:}

This work was supported by the Education Science Foundation of Liaoning Province, China during the 13th Five-Year Plan Period (Grant No. JG17DB084 ).

\section{References:}

[1] Chai Longhui, Xiao Xianghong, Zhang Jingwei, etc. Reflections on the Construction and Application of New Forms of Textbooks in the "Internet +" Era[J]. China Education Information. 2017,(2):50-52

[2] Chen Yin, Su Tonghua, Huang Hujie et al. Construction of a series of software engineering courses based on school-enterprise cooperation [J]. Computer Education. 2017, (3): 22-24

[3] Li Tianli, He Yi. On the Optimization of Network User Access Data Detection Simulation. Computer Simulation[J]. 2017,39(9):378-381 